\section{Facharztprüfung zur Erlangung des Schwerpunktes Neuropädiatrie zum Facharzttitel FMH für Kinder- und Jugendmedizin}

Aufgrund des Weiterbildungsprogrammes, welches am 1. Januar 1995 in Kraft gesetzt wurde, ist die Teilnahme an der Facharztprüfung für diejenigen Kandidatinnen und Kandidaten Voraussetzung für die Erlangung des Schwerpunktes Neuropädiatrie zum Facharzttitel FMH für Kinder- und Jugendmedizin, welche ihre Weiterbildung in Neuropädiatrie bis am 31. Dezember 1995 nicht abgeschlossen hatten. Es empfiehlt sich, die Facharztprüfung frühestens im letzten Jahr der reglementarischen Weiterbildung abzulegen (Art. 22 WBO).

Ort und Datum: werden nach Eingang der Anmeldungen, abhängig von gewünschter Prüfungssprache, festgelegt.

Prüfungsgebühr: die Fachgesellschaft erhebt eine Prüfungsgebühr von Fr. 400.-.

Anmeldung: unter Beilage des Curriculums an: Prof. E. Boltshauser, Uni-Kinderklinik, Abteilung Neurologie, Steinwiesstrasse 75, 8032 Zürich, Tel. 0126673 30, Fax 012667163.

Anmeldeschluss: 31. Mai 2001

\section{Examen de spécialiste en vue de l'obtention de la formation approfondie en neuropédiatrie à adjoindre au titre de spécialiste FMH en pédiatrie}

Selon le programme de formation postgraduée entré en vigueur le $1^{\text {er }}$ janvier 1995, la participation à l'examen de spécialiste est une condition requise pour les candidats à l'obtention de la formation approfondie en neuropédiatrie à adjoindre au titre de spécialiste FMH en pédiatrie qui n'avaient pas encore terminé leur formation postgraduée en neuro- pédiatrie le 31 décembre 1995. Il leur est recommandé de passer l'examen de spécialiste au plus tôt durant la dernière année de leur formation postgraduée réglementaire (art. 22 RFP).

Lieu et date: le lieu ainsi que la date de l'examen seront communiqués après réception des inscriptions et en fonction de la langue dans laquelle le candidat souhaite passer l'examen.

Taxe d'examen: la société de discipline médicale prélève une participation aux frais de Fr. 400.-.

Inscription: accompagnée de votre curriculum auprès du Prof. E. Boltshauser, Uni-Kinderklinik, Abteilung Neurologie, Steinwiesstrasse 75, 8032 Zurich, tél. 0126673 30, fax 012667163.

Délai d'inscription: 31 mai 2001 